\title{
Freud como lector de Nietzsche. La influencia de Nietzsche en la obra de Freud ${ }^{1}$
}

\section{Freud as Nietzsche's reader. Nietzsche's imfluence on Freud's work}

Recibido: 03 de marzo de 2015- Revisado: 25 de junio de 2015 - Aceptado: 21 de septiembre de 2015

Leandro Drivet ${ }^{2}$

\section{Resumen}

Este artículo pretende contribuir a la comprensión de la índole de la influencia del pensamiento nietzscheano en la obra de Freud. Para cumplir con este objetivo se realiza un análisis exhaustivo de los textos de Nietzsche y de Freud, se examinan las respectivas biografías y se revisa la bibliografía especializada en los vínculos entre ambos autores. Con base en las evidencias recogidas, se concluye con una reflexión que elabora la compleja relación de Freud con Nietzsche desde el concepto de lo ominoso, que es clave para entender la historia y la deriva del pensamiento freudiano.

\section{Palabras clave}

Teoría social crítica, historia del psicoanálisis, Friedrich Wilhelm Nietzsche, Sigmund Freud.

\section{Abstract \\ This article aims to contribute to the understanding of the nature of the influence of Nietzsche's thought in the work of Freud. To meet this objective a thorough analysis of the texts of Nietzsche and Freud is done, the respective biographies are examined and the specialized bibliography about the links between the two authors is reviewed. Based on the evidence gathered, we conclude with a reflection that deals with the complex relationship of Freud to Nietzsche from the concept of the abominable, which is key to understand the history and drift of Freudian thought.}

\section{Keywords}

Critical social theory, history of psychoanalisis, Friedrich Wilhelm Nietzsche, Sigmund Freud.
1 Este trabajo se redactó en el marco de la beca posdoctoral otorgada al autor por el Consejo Nacional de Investigaciones Científicas y Técnicas (CONICET) en el periodo 2014 2016.

${ }^{2}$ Doctor en Ciencias Sociales de la Universidad de Buenos Aires, Buenos Aires, Argentina. Investigador de CONICET, miembro del Centro de Investigación en Filosofía Política y Epistemología (CIFPE) y del Centro de Investigaciones Sociales y Políticas (CISPO). Docente de la Facultad de Ciencias de la Educación de la Universidad Nacional de Entre Rios (UNER), Concepción del Uruguay, Argentina; y de la Facultad de Humanidades, Artes y Ciencias Sociales (UADER). Sus investigaciones se ocupan de temas comunes al Psicoanálisis, la Filosofía y las Ciencias Sociales. Correo Electrónico: leandrodrivet@yahoo.com.ar

Para citar este artículo use: Drivet, L. (2015). Freud como lector de Nietzsche. La influencia de Nietzsche en la obra de Freud. Revista Civilizar Ciencias Sociales y Humanas, 15(29), 197-214. 


\author{
[...] será interesante averiguar el efecto \\ que nos produce toparnos con la imagen de \\ nuestra propia persona sin haberla invocado \\ e insospechadamente. \\ Freud (1919, 1999, p. 247)
}

La influencia de la filosofía de Nietzsche sobre el pensamiento de Freud es poco menos que indiscutible, y no solo porque luego de 1890 y especialmente durante los primeros años del siglo XX era imposible sustraerse del conocimiento del autor del Así habló Zaratustra en los círculos intelectuales europeos. Freud fue un reservado lector de Nietzsche, e intentó dar tratamiento científico a cuestiones planteadas a su modo por Nietzsche. Varios autores han demostrado conexiones temáticas (la interpretación de los sueños, la genealogía de la cultura, la crítica religiosa, entre otras) que los sitúan en un espacio común de teorización (los más sistemáticos: Assoun, 1980, 1984; Gasser, 1997; Lehrer, 1995; Miranda de Almeida, 2005; Vartzbed, 2003) ${ }^{1}$.

No obstante, persiste el enigma acerca de la índole del vínculo, problemático, apasionado y saturado de sobredeterminaciones, que el creador del psicoanálisis estableció con su predecesor. Para echar luz sobre este asunto será necesario recurrir a las evidencias que, ni escasas ni unívocas, habilitaron y habilitan una variada gama de especulaciones, para luego formular nuestra propia interpretación al respecto. A continuación, rastreamos las ocasiones en las que la marca de Nietzsche se revela en la escritura freudiana, evaluamos la relevancia de la influencia nietzscheana en la historia del psicoanálisis y concluimos con una hipótesis psicoanalítica acerca de la naturaleza de dicha relación.

Nacido en 1844, Nietzsche era doce años mayor que Freud (1856), distancia generacional que parece aumentada debido a la precocidad del filósofo. Nunca se conocieron. Nietzsche murió cuando Freud acababa de publicar $L a$ interpretación de los sueños, aunque hacía ya una década que el primero había roto lazos con este mundo. No obstante, Nietzsche está presente en los grandes giros del pensamiento freudiano. Cuando en la carta del 21 de septiembre de 1897 comunica a Wilhelm Fliess lo que parece un total abandono de la teoría de la seducción, y se encamina al descubrimiento de las fantasías inconscientes y de los deseos incestuosos infantiles (no sin un incesante coqueteo con el biologismo), Freud (1994) expresa: "En esta conmoción de todos los valores solo lo psicológico ha permanecido incólume"”2 (p. 286; cursivas del autor).

No puede ser fortuito que el amigo, discípulo y biógrafo Ernest Jones (1959) describa del siguiente modo ese hallazgo: "Estaba empezando a comprender la verdad de la máxima de Nietzsche: 'El propio ser es algo que a uno mismo se le oculta: de todos los tesoros ocultos el de sí mismo es el último en ser desenterrado"" (p. 334). Ya antes, el 31 de mayo de 1897, Freud escribía, con resonancias nietzscheanas, en pleno auge del filósofo: "Una vislumbre me dice además como si yo lo supiera ya -pero nada sé- que próximamente descubriré la fuente de la moral" (Freud, 1994, pp. 266-267).

Esta "intuición" haría sospechar a cualquier psicoanalista, y ya veremos que también a cualquier historiador. En ese momento se cumplían diez años de la publicación de $L a$ genealogíade la moral y sereeditaban Aurora, $L a$ ciencia jovial y Así habló Zaratustra. Además, Fliess pertenecía a los círculos nietzscheanos de Berlín, y fue a través de su recomendación que Freud conoció la producción literaria de C. F. Meyer, a quien Fliess presenta como un mentor de Nietzsche (Gómez, 1994). En consecuencia, las breves alusiones a la obra nietzscheana en la correspondencia citada pueden interpretarse como sobreentendidos.

En 1900, según informa él mismo (Freud, 1994, p. 437), Freud adquiere las Obras completas de Nietzsche, en las cuales esperaba "encontrar las palabras para mucho de lo 
que permanece mudo en mí”. El desgano que, según sus términos, le impide leer al autor de La genealogía de la moral contrasta con su inmensa capacidad de trabajo ${ }^{3}$. En la Contribución a la historia del movimiento psicoanalítico (Freud, 1914, 2003a, p. 15) afirma, después de reconocer la coincidencia entre su concepto de represión y la descripción schopenhaueriana de la locura como renuencia a aceptar un fragmento penoso de la realidad, y una vez que hubo agradecido a su "falta de erudición libresca, que me posibilitó hacer un descubrimiento": "En una época posterior, me rehusé el elevado goce de las obras de Nietzsche con esta motivación consciente: no quise que representación-expectativa de ninguna clase viniese a estorbarme en la elaboración de las impresiones psicoanalíticas" (Freud, 1914, 2003a, p. 15) ${ }^{4}$. Un psicoanalista podría preguntar(se) por las motivaciones inconscientes, cuando no más llanamente por las conscientemente silenciadas. El vienés repite esta versión hacia 1925:

En cuanto a Nietzsche, el otro filósofo cuyas intuiciones e intelecciones coinciden a menudo de la manera más asombrosa con los resultados que el psicoanálisis logró con trabajo, lo he rehuido durante mucho tiempo por eso mismo; me importa mucho menos la prioridad que conservar mi posición imparcial (Freud, 1925, 1998, p. 56).

Aquí enuncia (otra vez) con ambigüedad su relación con Nietzsche: ¿qué quiere decir haberlo rehuido "durante mucho tiempo"? ¿Hasta cuándo duró esa evitación? ¿Alguna vez concluyó, como parece entenderse? Cuanto menos, no se refiere de modo tajante a una distancia ininterrumpida. Leyendo este pasaje, Derrida $(1980,1986)$ habla directamente de la denegación de una "herencia intolerable" (pp. 19-21). ¿Pero qué es lo que la hace intolerable? Sobre esta intuición apenas desarrollada volveremos hacia el final.

Mientras tanto, la versión oficial de Freud puede complementarse y precisarse: el padre del psicoanálisis participó en las reuniones de los miércoles en la Sociedad Psicoanalítica de Viena (SPV) (Federn \& Nunberg, 1962, 1967, $1974,1975)^{5}$ en las que hacia 1908 Nietzsche o alguna de sus obras fueron el tema de discusión ${ }^{6}$, $\mathrm{y}$ en las que se advirtieron las similitudes de su pensamiento con el psicoanálisis. Pero el padre de la tribu psicoanalítica volvió a negar allí que Nietzsche hubiera influido en sus investigaciones.

$\mathrm{Su}$ testimonio es curioso: por un lado, atribuye su alejamiento de Nietzsche no al desinterés sino al "exceso de interés" (citado por Assoun, 1980,1984, p. 19) que le suscitaba, y que podría haber ido en desmedro de la imparcialidad o la libertad para investigar sin prejui$\operatorname{cios}^{7}$; pero, por otro lado, opina sobre la vida de Nietzsche haciendo hincapié en la fijación materna y el complejo materno, rechaza los intentos descalificatorios de Hitschmann de reducir la obra a ser un síntoma de la enfermedad, alude a las inclinaciones homosexuales y narcisistas que, junto con la parálisis progresiva que sufriera hasta morir, habrían alimentado la tendencia de Nietzsche a analizar las percepciones endopsíquicas, y así, en lugar de tratarlo como enfermo para desestimarlo a él o a su obra, concluye Jones (1960), le rinde un "hermoso cumplido" al declarar que "el conocimiento que Nietzsche tenía de sí mismo era tan penetrante que superaba al de todo otro ser viviente conocido y acaso por conocer" (p. 362). Esto equivale a reconocerlo como el primer psicólogo, si no como el primer psicoanalista. Sin embargo, las contradicciones en que incurre Freud cuando se refiere a Nietzsche son evidentes. ¿Cómo juzga la similitud de las ideas de Nietzsche con las del psicoanálisis si no lo ha leído? La siguiente afirmación de Freud, del 28 de octubre de 1908 en la SPV, descarta la posibilidad de que ignorara el pensamiento nietzscheano: "Lo que nos molesta es el hecho de que Nietzsche transformó 'ser' (ist) en 'deber' (soll). Pero semejante 'deber' es ajeno a la ciencia. En este sentido, Nietzsche fue un moralista y no pudo librarse del teólogo" (citado por Assoun, 1980, 1984, p. 254). Las sospechas alcanzan su hipérbole 
cuando Freud expresa que Nietzsche no captó el infantilismo ni el mecanismo del desplazamiento (Roazen, 2001, p. 568). No parecemos estar frente a una observación puntual sobre un breve fragmento. Esto suena como un balance de la obra de un pensador sobre el que, dice, no ha leído.

La sospecha que existe sobre sus lecturas silenciosas se acrecienta si nos remontamos a la juventud freudiana. Ronald Lehrer (1995) da cuenta de que en 1875, un Freud jovencísimo cita en la correspondencia con su amigo Eduard Silberstein pasajes de la primera intempestiva de Nietzsche, publicada en 1873. Freud fundó junto a unos amigos una sociedad de lectores, a la que perteneció hasta su disolución en 1878. En ella se admiró particularmente a Schopenhauer, Wagner y Nietzsche. Siegfried Lipiner, Heinrich Braun, Victor Adler y Joseph Paneth fueron los integrantes que estuvieron fuertemente impresionados por el oriundo de Röcken ${ }^{8}$.

Paneth, amigo de Freud hasta la muerte del primero en 1890, fue quien reemplazó a Freud en el laboratorio de Ernst Brücke cuando el futuro creador del psicoanálisis se convenció de que su promoción allí era improbable. La amistad entre Paneth y Freud está certificada por el propio Freud, quien nunca dejó de hablar con afecto de "mi (difunto) amigo P." (Freud, 1900, 1991, p. 422). Paneth mantuvo en Niza y por un breve periodo una relación personal con Nietzsche, a quien admiraba, al mismo tiempo que cultivaba su amistad con Freud. Les escribía a ambos al mismo tiempo y, como documenta Yerushalmi (1991, 1996), Freud participó de la boda judía de Paneth y Sophie Schwab en 1884, poco después de la estancia de Paneth en Niza.

Las cartas de este a su prometida testimonian con gran emoción ese encuentro con Nietzsche en el momento en que este había escrito las dos primeras partes de Asi habló Zaratustra y se disponía a emprender la tercera (Gasser, 1997, p. 31). Las cartas que Paneth le enviara a Freud no se han conservado, pero una pequeña huella mnémica del psicoanalista permite entrever su contenido. Así lo recordaba Freud en su senectud, en su correspondencia con Arnold Zweig el 12 de mayo de 1934: "Durante mi juventud, Nietzsche significó para mí algo así como una personalidad noble [una nobleza] ${ }^{9}$ y distinguida que me era inaccesible. Un amigo mío, el doctor Paneth lo había conocido personalmente y me escribió muchísimo acerca de él”. (Freud \& Zweig, 2000, p. 106).

La información de esas cartas estaba presente en la memoria de Freud cuando se negó a alimentar el prejuicio de los médicos en su intento de etiquetar a Nietzsche con un diagnóstico clínico para conjurar su pensamiento. ¿Le escribiría "muchísimo" sobre Nietzsche a un desinteresado en el tema? ¿Podría haber eludido al hacerlo el pensamiento de Nietzsche, siempre uno y el mismo con su vida? Ernst Nolte (1990) confiere a este vínculo una significación mayúscula:

El invierno de 1883-84 lo pasó Nietzsche, hasta abril, en Niza. Aquí recibió la visita de Joseph Paneth, amigo y alumno de Sigmund Freud, de la que quizás sea lícito concluir que las posteriores aproximaciones entre nietzscheanismo y freudianismo no fueron meramente casuales (p. 72).

De estas líneas podemos encaminarnos a suponer que Freud no solo fue un temprano y cauteloso lector de Nietzsche, sino tal vez el primero que no se limitó a realizar una exégesis del filósofo.

Estas vivencias juveniles parecen súbitamente reflotadas durante la visita que hace Freud en 1898 a la Engadina, lugar de veraneo de Nietzsche y donde escribió la segunda parte de Asi habló Zaratustra y, más tarde, El crepúsculo de los ídolos. El paseo del vienés por los altos valles suizos coincide con el momento en que se produce su identificación onírica con el superhombre y la rememoración de la Leseverein (Gómez, 1994). Todo esto hace comprensible 
y casi inevitable la presencia de Nietzsche en la obra madre de Freud. En La interpretación de los sueños, hacia el final del pasaje sobre los medios de figuración del sueño, Freud expresa que entre el material onírico y el texto que lo expresa no hay una traducción pacífica sino conflictiva: "La intensidad de los elementos en uno nada tiene que ver con esa intensidad en el otro; entre material onírico y sueño ocurre de hecho una total 'subversión de todos los valores psíquicos"”. (1900, 1991, pp. 334-335)

Strachey (citado por Freud, 1900, 1991, p. 335n) no duda en interpretar las cursivas de Freud como una "Alusión al célebre leitmotiv del ataque lanzado por Nietzsche contra el cristianismo". Y es el propio Freud el que, en el trabajo titulado Über den traum, confirma la identidad del proceso descrito por él como "desplazamiento" y la operación que Nietzsche llama "inversión de los valores": "Lo que he llamado 'desplazamiento onírico' pude designarlo también subversión de las valencias psíquicas" (Freud, 1901, 1991, p. 637) ${ }^{10}$. Pero mucho antes de El anticristo, en la sección cuarta de El nacimiento de la tragedia, el joven Nietzsche (2004) escribió sobre la índole transvaloradora del sueño ${ }^{11}$. Más adelante en la Traumdeutung, al referirse al "carácter regrediente" de los sueños e interpretarlos como la expresión de una memoria pre-histórica del sujeto y de la civilización, Freud apela a Nietzsche:

El soñar en su conjunto es una regresión a la condición más temprana del soñante, una reanimación de su infancia, de las mociones pulsionales que lo gobernaron entonces y de los modos de expresión de que disponía. Tras esta infancia individual, se nos promete también alcanzar una perspectiva sobre la infancia filogenética, sobre el desarrollo del género humano, del cual el del individuo es de hecho una repetición abreviada, influida por las circunstancias contingentes de su vida. Entrevemos cuan acertadas son las palabras de Nietzsche: en el sueño "sigue actuándose una antiquísima veta de lo humano que ya no puede alcanzarse por un camino directo"; ello nos mueve a esperar que mediante el análisis de los sueños habremos de obtener el conocimiento de la herencia arcaica del hombre, lo que hay de innato en su alma. Parece que sueño y neurosis han conservado para nosotros de la antigüedad del alma más de lo que podríamos suponer, de suerte que el psicoanálisis puede reclamar para sí un alto rango entre las ciencias que se esfuerzan por reconstruir las fases más antiguas y oscuras de los comienzos de la humanidad (Freud, 1900, 1991, p. 542).

El pasaje que Freud cita (aparentemente de memoria) forma parte del fragmento número 13 del primer tomo de Humano, demasiado humano, tercero, después del quinto y el duodécimo, en el que Nietzsche $(1878,2007 a)$ brinda notas para una interpretación de los sueños. Assoun $(1980,1984)$ advierte que mientras que la teoría del sueño de Schopenhauer está ubicada en la reseña histórica de La interpretación de los sueños, Nietzsche es citado en el capítulo central.

Freud conocía parte de la obra de Nietzsche, de primera mano o por referencias de su círculo más próximo. Cualquiera que haya tenido alguna aproximación a Nietzsche sabe que no hace falta haber leído el conjunto de su obra para acceder a la totalidad de sus temas o problemas. La historia de esta extraña pareja continúa, y nos permitirá volver inteligible que Nietzsche sea el filósofo del que Freud se lleva más textos a su morada definitiva, en 1938 (Gómez, 1994). De 1910 es también una nota al pie en la que Nietzsche aparece como una cita de autoridad en el contexto de la explicación de que no solo las personas enfermas sino también las sanas, tienden a dejar caer en el olvido los recuerdos penosos:

Pero ninguno de nosotros ha podido describir el fenómeno, ni su fundamento psicológico, de manera tan exhaustiva e impresionante a la vez como Nietzsche en uno de sus aforismos (Jenseits von gut und böse [Más allá del bien $y$ del mal], IV, 68): “'Yo lo he hecho', dice mi memoria. 'Yo no puedo haberlo hecho', dice mi orgullo, y se mantiene inflexible. Al fin... cede la memoria" (Freud, 1901,2006a, pp. 145-146). 
Nietzsche reaparece cuando Freud examina el delirio de Daniel Paul Schreber, quien vinculando simbólicamente al padre con el sol muestra que hay correspondencias entre las fantasías de los sujetos neuróticos y los mitos cósmicos. En el delirio, el Sol habla con palabras humanas, insulta e increpa a Schreber. Freud (1911, 2006b) concluye:

No soy responsable por la monotonía de las soluciones psicoanalíticas si aduzco que el Sol, a su vez, no es otra cosa que un símbolo sublimado del padre. El simbolismo se establece aquí con prescindencia del género gramatical; en alemán, quiero decir, pues en la mayoría de las otras lenguas "Sol" no es femenino, sino masculino. Su contraparte en este espejamiento de la pareja parental es la "Madre Tierra", así calificada universalmente. En la resolución psicoanalítica de fantasías patógenas en neuróticos uno halla corroborada esta tesis con harta frecuencia [...] Por una de mis pacientes, que había perdido a su padre muy temprano y buscaba reencontrarlo en todo lo grande y sublime de la naturaleza, he considerado probable que el himno de Nietzsche "Antes del nacimiento del Sol" expresara esa misma añoranza (p. 51).

En nota al pie, Freud refiere con precisión el himno mencionado en la Parte III de Asi habló Zaratustra, y agrega: "También Nietzsche conoció a su padre solo cuando niño" (Freud, 1911, 2006b, p. 51). Del desconocimiento de Nietzsche pasamos ahora a la cita erudita y a los esbozos de su interpretación psicoanalítica.

Lou Andreas Salomé constituye el segundo de los vínculos personales entre Nietzsche y Freud, después del de Joseph Paneth. El encuentro con aquella ocurre hacia 1912, en el Congreso de Weimar ${ }^{12}$. Freud la supo un nexo real entre Nietzsche y él mismo, y expresó a Zweig que ella "jamás quiso hablarme de él" (Freud \& Zweig, 2000, p. 104), lo que sugiere intentos de hacerlo por parte de Freud. Pero el silencio interpuesto por Lou es tan cierto como Friedrich Nietzsche en sus obras (Andreas Salomé, 1894, 2005), el libro de su autoría publicado en 1894, del que Freud pudo extraer un conocimiento erudito y sinóptico del pensamiento de Nietzsche.

Este es descrito allí como alguien propenso a someter lo lógico a lo psicológico, y como el psicólogo más fino de todos para captar y modelar matices. Habiendo estudiado con Nietzsche, a quien conoció siendo una joven de 21 años, Lou Andreas-Salomé se convertiría luego en una amiga entrañable de Freud, admiradora y defensora del psicoanálisis, psicoanalista destacada e intelectual prolífica, hasta su muerte en 1937.

La presencia de Nietzsche en las reflexiones freudianas nunca cesa. Hacia el final de "Algunos tipos de carácter dilucidados por el trabajo psicoanalítico", Freud (1916, 2003b) se refiere a "Los que delinquen por conciencia de culpa" como aquellas personas que cometen una fechoría para aliviar una conciencia de culpa previa, de origen desconocido para sí mismos. El delito les permite fijar el sentimiento de culpa a un acto y así disminuir el agobio culpógeno al racionalizarlo. El descubrimiento es atribuido retrospectivamente por Freud a Nietzsche:

Un amigo me ha hecho notar después que el "delincuente por conciencia de culpa" era conocido también por Nietzsche. La preexistencia del sentimiento de culpa y el recurso a la falta para su racionalización (que aplaca la angustia) son patentes en el relato de Zaratustra "Sobre el pálido delincuente" (Freud, 1916, 2003b, p. 339) ${ }^{13}$.

La mención de Nietzsche retorna en Psicología de las masas y análisis del yo:

En los albores de la historia humana él fue el superhombre que Nietzsche esperaba del futuro. Todavía hoy los individuos de la masa han menester del espejismo de que su conductor los ama de manera igual y justa; pero al conductor mismo no le hace falta amar a ningún otro, puede ser de naturaleza señorial, absolutamente narcisista, pero seguro de sí y autónomo (Freud, 1921, 2004a, p. 118). 
La comparación entre el padre de la horda y el superhombre es osada y revela, por un lado, la lectura de Así habló Zaratustra y, por otro, una interpretación discutible del concepto nietzscheano ${ }^{14}$ como un monstruo mítico portavoz deuna ilusión religiosa. El superhombre del pasado es para Freud inherentemente anticultural; representa el rechazo de toda moral, la exaltación del principio de placer y la liberación de las agresiones sin inhibición. Al tiempo que construía su genealogía de la moral, Freud intentaba explicar al "superhombre" del modo en que desentrañó la idea de Dios, cosa que se sigue del siguiente fragmento, en el que Freud (1920, 2006c) descarta la fe en el progreso moral con estas palabras:

A muchos de nosotros quizá nos resulte difícil renunciar a la creencia de que en el ser humano habita una pulsión de perfeccionamiento que lo ha llevado hasta su actual nivel de rendimiento espiritual y de sublimación ética, y que, es lícito esperarlo, velará por la transformación del hombre en superhombre. Solo que yo no creo en una pulsión interior de esa índole, y no veo ningún camino que permitiría preservar esa consoladora ilusión (p. 41) ${ }^{15}$.

El término "superhombre idealizado" como sinónimo de Dios vuelve a aparecer cuando somete a la religión a un examen genético, y la compara con la filosofía (Freud, 1933, 2006d, p. 150). ¿Puede dudarse de que Freud tuviera en mente a Nietzsche? El margen de incertidumbre se estrecha cuando advertimos que pocas páginas antes de manifestar su desconfianza en el superhombre en Más allá del principio del placer, Freud (1920, 2006c, p. 22) se refiere a la presencia de repeticiones que actualizan vivencias displacenteras desde su origen como el "eterno retorno de lo igual", expresión que él coloca entre comillas.

El entrecomillado confirma que se trata de un concepto ajeno, aunque el sentido que Freud le da a la idea es irónico. Y ya en "Lo ominoso" Freud (1919, 1999, p. 234) se había aproximado a esta idea del "permanente retorno de lo igual"16, que oscilaba entre la compulsión obsesiva sustitutoria de la acción prohibida y el concepto de la pulsión de muerte. El origen nietzscheano de la idea es más evidente cuando se considera que en 1920 Freud relee y valora la tesis que Sabina Spielrein $(1912,1995)$ había enunciado en 1912 en un breve trabajo en el que Nietzsche es mencionado... i24 veces! Junto al superhombre, el eterno retorno: un año más tarde, como vimos, el superhombre sería invocado junto a la muerte de Dios-Padre (primitivo).

Freud vuelve a apelar a Nietzsche para encontrar palabras para lo que se hallaba mudo en él mismo, cuando en 1923 sistematiza la segunda tópica e introduce el concepto de "ello", tomado de Georg Groddeck, pero a sabiendas de su verdadera proveniencia: "El propio Groddeck sigue sin duda el ejemplo de Nietzsche, quien usa habitualmente esta expresión gramatical para lo que es impersonal y responde, por así decir, a una necesidad de la naturaleza, de nuestro ser" (Freud, 1923, 2006e, p. 25).

Llama mucho la atención que alguien que no lee a Nietzsche, o que, según sus declaraciones, apenas ha podido leer una página antes de sentirse obligado a abandonarlo, conozca los usos habituales de una expresión nietzscheana. Esta declaración obliga a suponer que la privación autoimpuesta de estudiar al filósofo había tenido un punto final en algún momento. La conexión con el genealogista de la moral no es terminológica, ocasional ni accidental, como parece racionalizar Freud, sino conceptual, permanente y estructural, como puede advertirse de la lectura paralela de La genealogía de la moral (Nietzsche, 1887, 2008) y El malestar en la cultura (Freud, 1930, 2004c) (Greer, 2002). Sin embargo, no habría que llamarse a engaño suponiendo un plagio de Freud: no nos encontramos ante una emulación burda del pensamiento nietzscheano. La voluntad de Freud puede leerse en otro enunciado: "no nos arredrará indicarle a la intelección de Groddeck su lugar 
en la ensambladura de la ciencia" (Freud, 1923, 2006e, p. 25). Esto es lo que el psicoanalista quiere hacer con Nietzsche, lo cual no puede dejar intocado el edificio de su ciencia, que en 1923 adquiere un aspecto nietzscheano más notorio.

La diferencia entre el Ello de Groddeck y el ello freudiano alberga la discusión sobre la libertad del individuo, tema que se evidencia en la distancia entre el determinismo psíquico (Freud, 1901, 2006a) y el fatalismo al que adscribe Groddeck $(1923,1973)$ cuando sostiene que somos vividos por el Ello. Peter Gay (2010, pp. 459-460) trae a colación de este diferendo la ironía gentil con que Freud saluda a Groddeck en su cumpleaños número sesenta: "Mi yo y mi ello felicitan a su Ello".

De lo anterior no pretendemos reducir la compleja trama del pensamiento freudiano, cuyas fuentes son amplias y diversas, a la influencia de Nietzsche. Tampoco es posible cubrir las relaciones del psicoanálisis con el pensamiento nietzscheano con una sospecha de mala fe: esta relativizaría las invaluables conquistas de la creación freudiana, que jamás abandonó su fe en la ilustración ni sus pretensiones de cientificidad. En primer lugar, hay razones ideológicas que explican la incomodidad de Freud frente a Nietzsche, y que sin duda motivaban su necesidad de diferenciarse de este. Estas razones suelen pasarse por alto en las hagiografías intelectuales de uno y de otro.

Un judío liberal como Freud no podía identificarse con el aristocratismo nostálgico de Nietzsche, aunque sí con sus sueños de grandeza. Despreciaba las pretensiones nobiliarias con las que en cambio soñaba el filósofo, así como la tolerancia o incluso la aceptación del esclavismo (en la forma del desprecio de los intentos de abolirlo) que también se encuentran en Nietzsche. Tampoco admitía el elitismo espiritual del autor de El anticristo, que pugnó por la diferencia entre la selecta kultur y la plebeya zivilisation, distinción que el psicoanalista rechazó explíci- ta y lacónicamente al comienzo de El porvenir de una ilusión. Mucho menos podía simpatizar Freud con el coqueteo con el antisemitismo que, si acaso no Nietzsche, sí practicaron muchos de sus lectores, incluso de los más refinados ${ }^{17}$.

En parte, además, la supresión del nombre de Nietzsche del horizonte freudiano no es diferente de otros olvidos quizá menos sugerentes. Peter Gay $(1988,2010$, p. 711) comenta que cuando un corresponsal de Palestina, Israel Dorion, le sugirió a Freud que era posible que hubiera adoptado la idea de que Moisés era egipcio después de haberla leído en un texto de Josef Popper-Lynkeus, Freud no se fastidió; al contrario, se interesó pensándolo como un fenómeno que llamó criptomnesia (una especie de robo inconsciente e inocente). No dejaba de contentarse afirmando que su originalidad era apenas un refuerzo psicoanalítico a una idea antigua. El mismo fenómeno psíquico podría echar luz sobre algunas coincidencias con Nietzsche, y no necesariamente restarían a Freud el mérito de haber sido el primero que prestó oídos, y luego formas de expresión siempre preocupadas por colaborar con la comprensión de los lectores, de la sutil escritura de un pensador condenado por décadas al silencio y a la incomprensión.

No obstante, creemos distinguir mejor la índole del vínculo que los une y que los separa cuando no disimulamos nuestra incomodidad frente a la generalización de la hipótesis de la criptomnesia. Psicoanalíticamente, un olvido no explica: debe ser explicado. Y, psicoanalíticamente, la relación de Freud con Nietzsche parece atravesada por lo ominoso. Roazen (1993, p. 89) nos acerca a esta idea, aunque no la desarrolla, cuando expresa que "the resemblances between Nietzsche and Freud are so close as to be almost uncanny". Y algo similar descubre Vartzbed (2003): "Freud se comporter à l'égard de Nietzsche comme s'il était en présence d'un double inquiétant" (sabido es que el tópico literario del "doble" es uno de los ejemplos a partir de los cuales Freud se aproxima al esclarecimiento de ese sentimien- 
to que llama das unheimliche). ¿Y si Freud lo hubiera confesado en privado? ¿Y si hubiera dado muestras de un temor ante la amenaza del doble? (p. 351). Una declaración jamás citada respecto de este tema, pero que cabría enlazar a él, resulta iluminadora:

Tengo, no obstante, que hacer una confesión, que le ruego no divulgue ni comparta con amigos ni enemigos. Me he atormentado a mí mismo preguntándome por qué en todos estos años jamás había intentado que trabáramos amistad ni charlar con usted (ignorando, naturalmente, la posibilidad de que no hubiera usted acogido bien mi intentona).

La respuesta contiene esta confesión, que me parece demasiado íntima. Creo que le he evitado porque sentía una especie de reluctancia a encontrarme con mi doble. No es que me sienta normalmente inclinado a identificarme con otra persona, ni que deje a un lado la diferencia de talento que me separa de usted; pero siempre que me dejo absorber profundamente por sus bellas creaciones paréceme hallar, bajo su superficie poética, las mismas anticipadas suposiciones, intereses y conclusiones, que reconozco como propios. Su determinismo y su escepticismo -que la gente llama pesimismo-, su preocupación por las verdades del subconsciente y los impulsos instintivos del hombre, su disección de las convenciones culturales de nuestra sociedad, la obsesión de sus pensamientos sobre la polaridad del amor y la muerte, todo esto me conmueve, dándome un irreal sentimiento de familiaridad. [...] Así, he llegado a formar la impresión de que su intuición -o más bien una autoobservación detallada- le ha permitido llegar a aquello que yo he descubierto solo mediante un trabajo laborioso de observación de otras personas. Estimo que, fundamentalmente, su naturaleza es la del explorador de profundidades psicológicas, tan honradamente imparcial y objetivo como el que más, y que si no hubiera poseído tal constitución, sus facultades artísticas, sus dotes idiomáticas y su poder de creación hubieran ejercido mayor efecto sobre usted, convirtiéndole en escritor de más atractivo para el gusto de las masas. Me inclino a dar preferencia al explorador.
Este fragmento de la carta a Arthur Schnitzler del 14 de mayo de 1922 (Freud, 1989, pp. 383-384), parece calcar lo que ocurre con Nietzsche, como si Freud se hubiera "decidido" a confesar un saber del que apenas se sabe (el pedido de reserva es la señal de angustia que provoca el fantasma), y por interpósita persona, la estructura afectiva que modeló su relación con quien habría sido, muy a su pesar, el primer psicoanalista. No tenemos pruebas históricas, más allá de la interpretación analítica de la escritura de Freud, para conectar esta declaración consciente con la figura de Nietzsche, que creemos produce en Freud una angustia análoga, más profunda y "verdadera" (en el sentido de lo inconsciente): inconfesable para su voluntad.

No obstante, podemos suponer dicho "irreal sentimiento de familiaridad" frente a la lectura de Nietzsche si recordamos que-solo tres años después de escribirle a Schnitzler- Freud (1925, 1998, p. 56) reconoce que este alcanzó por la vía de geniales intuiciones resultados que el psicoanálisis solo obtuvo tras mucho esfuerzo. Permítasenos conjeturar entonces, pese a la ausencia de mayores precisiones en el discurso de Freud, que frente a Nietzsche aquel era presa de una reluctancia similar, y veamos si esta hipótesis nos ayuda a atar los cabos sueltos que permitirían echar luz sobre los motivos de la resistencia evidente ante el caminante de Sils Maria.

No era la primera vez que Freud era asaltado por la ominosa impresión de enfrentarse a un sosías. Jones (1960) refiere que en un viaje a Nápoles Freud encontró en el tren a alguien que parecía su doble. Inmediatamente, envuelto en una angustia supersticiosa, preguntó a su hermano Alexander si esa experiencia significaría aquello de "Vedere Napoli e poi morire". ¿Podría ser que Freud recordara más o menos conscientemente haber leído, o quizá que fuera acometido por la reminiscencia de que se encontraba en la región en la que Nietzsche, escapando de las mortificantes jaquecas que lo sometían en Basilea, había decidido abandonar 
la filología para dedicarse a esa particular forma de la filosofía que es la psicología nietzscheana? ${ }^{18}$. Al menos no es imposible suponerlo.

Volviendo a lo efectivamente expresado, el objeto que despierta el horror sagrado que el psicoanalista confiesa en la carta que citamos no es Nietzsche sino otro; el sentimiento es el mismo, aunque atenuado bajo el representante "Schnitzler". La atenuación propicia la emergencia de la verdad negada, pero ya no exitosamente reprimida. Creemos no andar extraviados si atribuimos en parte dicha aminoración de la intensidad de la angustia al hecho de que Schnitzler no pretendía otra cosa que logros literarios.

Pese a la admiración y al provecho con que Freud recurría a la creación artística, el estatuto teórico del género que él mismo pretendía edificar se diferenciaba con claridad de la literatura. Nietzsche, en cambio, era mucho más difícil de clasificar exclusivamente como literato. Las metáforas con las que más de una vez ilustra su empresa lo definen como un explorador, figura ante la que Freud dice "inclinarse". Él mismo se contaba entre los filósofos, e incluso, las más de las veces, como el primer auténtico psicólogo, escrutador de las profundidades inconfesas. Entender a Nietzsche como psicólogo, en el sentido inaudible para un no psicoanalista que el autor de Asi habló Zaratustra exigía, era un horizonte que quizá solo Freud podía anticipar ${ }^{19}$.

Sin embargo, tampoco la mitigación "literaria" del doble reconocido resulta convincente para captar la singularidad de un horror sagrado que hunde sus raíces mucho más hondamente que en el orgullo narcisista por la autoría de una conquista intelectual. Para comprender el rasgo siniestro que evoca al psicoanalista la figura de Nietzsche, debemos escuchar la palabra pronunciada por el propio Freud; una palabra clave, ya referida aquí, que no por casualidad se resistió a la traducción: "Durante mi juventud -recordaba el adulto Freud en carta a Zweig-,
[Nietzsche] representaba para mí una nobleza fuera de mi alcance" (citado por Assoun, 1984, p. 40).

El nombre de Nietzsche se sintetiza en la polisémica expresión "nobleza inalcanzable". No es un secreto que en el pensamiento de Nietzsche la nobleza es el signo de un pasado grandioso, de la fortaleza y la profundidad del presente, y la esperanza de un futuro que se resiste a la mediocridad moderna, prolongación de la moral de esclavos de la cultura judaica y cristiana. La "moral del resentimiento" contra la que embiste el autor de La genealogía de la moral es una invención judaica que alcanza su más perfecta formulación en el judío Pablo de Tarso.

Al menos para la interpretación más radicalmente antisemita, más vulgar y monstruosa de esta tesis que poco después se haría del poder en gran parte de Europa, la grandeza nórdica de un aristócrata era, para el judío Freud, inalcanzable por motivos raciales-constitucionales. $\mathrm{La}$ admiración de la inmensa figura de Nietzsche -quien inclusive reclamaba para sí un origen noble, basándose en una dudosa etimologíatenía para Freud tonos vergonzantes. Una ley no escrita permitía venerarlo íntimamente como psicólogo, pero vedaba traspasar el reconocimiento público de ese escritor movilizador.

Esta ley es la que en la serie de intercambios epistolares que referimos mueve a Zweig a afirmar sobre Nietzsche: "Nunca fue otra cosa que un filólogo genial... las palabras lo hacían feliz, las palabras le bastaban por completo. ¡Pero pobres de nosotros cuando las coloca de manera que pongan en movimiento a los hombres!" (citado por Freud \& Zweig, 2000, p. 108). Y más adelante pronuncia, como escudándose en una declaración de principios que busca tranquilizar al destinatario: "Este F. Nietzsche ha sido uno de los grandes amores de mi juventud, lo he admirado como prosista e incluso como pensador, pero nunca más allá de Zaratustra” (p. 109). Nunca, puntualiza Zweig, más allá de Zaratustra: aquel profeta irreligio- 
so que tras el fracaso de la pedagogía muta en psicólogo. Nunca más allá del Zaratustra, ese magnífico reino de ensueño a resguardo de la sangre y la tierra; nunca donde comienza el peligroso territorio del Más allá del bien y del mal, La genealogía de la moral, El anticristo -y todo el proyecto, luego abandonado, de $L a$ voluntad de poder-, Ecce homo y, si no nos limitamos a la serie cronológica hacia "adelante", un más allá que comprende textos como Sobre el porvenir de nuestras instituciones educativas, El nacimiento de la tragedia y las "Intempestivas". Dicho de otro modo: la admiración no podía atravesar el punto más allá del cual se preparaba el hoy bien conocido "asalto a la razón” (Lukács, 1953, 1959). También la sensibilidad exquisita de Thomas Mann (1947, 2000, pp. 123-124), otro amigo de Freud que de ningún modo consideraba a Nietzsche un fascista, atestigua la presencia de la ley tácita a la que aludimos, ofreciendo con posterioridad razones que la explican:

Todo lo que Nietzsche dijo, en una sobreexcitación extrema, contra la moral, contra el humanismo, contra la compasión, contra el cristianismo, y a favor de la desvergüenza bella, a favor de la guerra, a favor del mal, era por desgracia apto para encontrar su puesto en la ideología de pacotilla del fascismo [...] Si es verdadera la frase que dice: "Por sus frutos los conoceréis", mal están las cosas para Nietzsche. (Thomas Mann, 1997, pp. 123-124).

El elogio del refinamiento y la inteligencia nietzscheanos se solapaba y se confundía peligrosamente, desde comienzos del siglo XX y en un crescendo vertiginoso hasta bien entrada la década de 1930, con las resonancias belicistas, irracionalistas y antisemitas que tuvieron ecos macabros. En esta atmósfera de vulgarización y barbarización racionalizada, Freud se arriesgaba a ser señalado como un guardián de la psicología-política nietzscheana, cuando solo aspiraba a preservar su verdad psicológica. ¿Habrá sopesado Freud la coincidencia de que ambos, él y Nietzsche, habían sido testigos, a una edad muy temprana, de la muerte de un hermano me- nor -a saber: Ludwig Nietzsche (1848-1850) y Julius Freud (1857-1858)-? ¿Qué importancia habrá tenido este factor en la propensión de Freud a empatizar con Nietzsche? ¿Quizá ese recuerdo del hermano menor muerto, al que Freud reconoció haber dirigido malos deseos, despertaba en él el temor de un destino similar como contracara culpógena de sus ansias de ocupar un lugar reservado a alguien "mayor"? No lo sabemos, y el caso es que ninguna intimidad podía servirle de coartada.

¿Cómo no sentirse culpable de la envidia de una "nobleza" por definición antijudaica, al tiempo que el mismo Dr. Freud se afanaba -por ejemplo depositando una confianza excesiva en Carl Jung, ese otro nietzscheano suizo, místico... antisemita, que encontró palabras en Asi habló Zaratustra cuando se decidió a romper con su maestro- en evitar que el psicoanálisis se limitara a ser considerado una "ciencia judía"? ¿Cómo soportar las miradas inquisitivas ante el reconocimiento de una filiación nietzscheana? ¿Cómo eludir las sospechas sobre una perfidia que lo alejaba de "los suyos" al tiempo que, al no poder escapar al "destino" de ser un "traidor", lo cristalizaba, pérfido entre los pérfidos, como un paradigma de lo judaico para el prejuicio cristiano-antisemita? ¿Cómo un "simple" judío como él podía soñar con participar de semejante comparación? Así, estaba doblemente en falta.

Por un lado: ¿cómo se atrevía a dilatar de este modo su orgullo? ¿O podía olvidar acaso que había sido su padre, Jacob Freud, el pequeño hombre que soportó sin rebelarse, tal como le narró a su atónito hijo, un humillante ataque antisemita en la vía pública que lo obligó a abandonar la vereda y a recoger el gorro de piel nuevo, arrojado al estiércol por el golpe de un gentil? ¿No sería al fin de cuentas esta persecutoria imagen de su doble solamente la reacción ante un sentimiento de inferioridad revestido malamente de sueños de grandeza?

Por otro lado: ¿cómo podía, a la vez, soportar la carga de esa pesadilla en la que se 
identificaba con el enemigo -ya no, como en tiempos de la Traumdeutung, con el semita Aníbal que juró vengar a Cartago-, y se convertía en un criminal-perseguidor de su estirpe? ¿Cómo se atrevería a desairar el mensaje de su padre, aquella dedicatoria, escrita en hebreo, firmada en la vieja Biblia familiar que le entregó restaurada, "como recuerdo y señal de amor" (citado por Yerushalmi, 1991, 1996, p. 153), en su trigésimo quinto cumpleaños? ¿Desoiría el dramático llamado paterno a regresar a los valores originalmente compartidos? ¿Renunciaría no solo a esas marcas primarias sino también a la conciencia judía a la que había despertado en sus años de universidad al percibir las acusaciones del antisemitismo germano por la crisis económica (Gay, 1988, 2010)? ¿No sería su vanidosa y arriesgada pretensión de ser un transvalorador de valores otra muestra, ¡una más!, de su inconfeso desprecio del judaísmo, al que en sucesivas estocadas despojaría de sus ropajes religiosos, hasta arrebatar incluso la novela de los orígenes (Freud, 1939, 2006f)?

Las escenas se superponen: vergüenza primera por la supuesta petulancia, externamente señalada, de creerse con iguales derechos que los "nobles"; segunda vergüenza, más tarde, al advertir el autodesprecio y la autocompasión aprendidos. Y sin embargo, su propio nombre, que tanto trabajo le había costado forjar, le impediría ceder en las convicciones filonietzscheanas que, contra todas las admoniciones de la compacta mayoría, y contra la angustia proveniente de la autoridad interiorizada, sostuvo hasta su muerte. El feroz anticatolicismo freudiano no podía sino simpatizar con el proverbial desprecio al cristianismo de Nietzsche, pero las convicciones liberales y científicas de Freud, forjadas contra las facciones antisemitas que pulularon en Viena especialmente después del "viernes negro" de mayo de 1873 que produjo la caída del "mercado de valores" -iprecisa denominación!-, contrastaban con el rechazo al liberalismo del segundo.

En suma: reconocer y celebrar a Nietzsche como doble-del-padre del psicoanálisis era in- desligable de levantar sobre Freud y, por carácter transitivo, sobre el psicoanálisis, la sospecha de alimentar el descrédito de la razón y el antisemitismo. El temor de Freud a igualarse con Nietzsche comprometía un temor por el destino epistemológico y político del psicoanálisis. Si Freud había reconocido en 1900 que se aproximaba a las obras de este filósofo a los efectos de encontrar palabras para mucho de lo que permanecía mudo en sí mismo, no podría luego dejar en silencio la angustiante idea, formulada al pasar precisa y significativamente en Psicología de las masas y análisis del yo, de que "primero uno cede en las palabras y después, poco a poco, en la cosa misma" (Freud, 1921, 2004a, p. 87). Pero no por ello daba concesiones a la cobardía, como si no pudiera deshacerse de la convicción de que, como había expresado un poeta, "allí donde se encuentra el peligro se halla también la salvación".

Ocurre ante Nietzsche como si Freud reclamara el derecho, que invocó cuando se vio seducido por los semblantes de la muerte, a entregarse a la argumentación y al pensamiento "solo por curiosidad científica o, si se quiere, como un advocatus diaboli que no por eso ha entregado su alma al diablo" (Freud, 1920, 2006c, p. 57). El amor por el saber colocaba al Fausto vienés ante la dificultad de gozar de un tesoro prohibido sin que su alma se transfigurase en el contacto con el mismo "Anticristo" ${ }^{20}$. ¿Y no sería tal vez la lectura de Nietzsche lo que suscitara una experiencia análoga de aquel temor ante la contemplación de lo "perfecto", como si Freud, poseído por el contacto con el tabú, escuchara la siniestra admonición: "Leggere Nietzsche e poi morire"?

Se trata de una identificación espinosa por donde se la mire: ese doble latente que es Nietzsche para Freud encarna una tentadora invitación a doblegarse. El temor reverencial que le produce se enlaza con sobredeterminaciones que atañen a los primeros lazos identitarios, a los que, en virtud de la seductora y criminal verdad a la que el psicoanalista siempre aspiró a honrar, 
no se puede sino poner en vilo. Lo motivaba en especial un "natural" rechazo de las extorsiones morales y políticas que promueven la represión, o los silencios convenientes. Por eso, si en la "Presentación autobiográfica", en plena efervescencia del nacionalismo antisemita que invitaba a la conversión o al ocultamiento de su linaje, había afirmado, lacónico y desafiante: "Mis padres eran judíos, y yo lo he seguido siendo" (Freud, 1925, 1998, pp. 7-8), en los umbrales de su muerte,

[...] escribiendo acerca de MRM [Moisés y la religión monoteista] a Charles Singer el 31 de octubre de 1938, Freud había exclamado, de manera característica: "No hace falta decir que tampoco me gusta ofender a mi pueblo. Pero, ¿qué puedo hacer con ello? Me pasé toda la vida defendiendo lo que consideraba la verdad científica, incluso cuando era incómoda y desagradable para mi semejante. No puedo terminar con un acto de repudio" (Yerushalmi, 1991, 1996, p. 34, n. 24, Cursivas del autor).

Sin poder jamás consumar un "acto de repudio", ni -tampoco- un gesto pleno de gratitud como homenaje abierto y profundo, el autor de La interpretación de los sueños ofrece la verdad de la relación con Nietzsche con todas las características de lo ominoso. Y precisamente por la irresolución del ser entre lo íntimo y lo extraño, hay un halo de tragedia en el acecho del padre de la "voluntad de poder" a la identidad freudiana: aquel aparece en el pensamiento de Freud como un "destino" inevitable, Moira que es, psicoanalíticamente, el cumplimiento de un deseo (reprimido), de una pulsión, de vida o de muerte, que alcanza satisfacción. En el contexto del asedio insistente de este doble transvalorador a las identificaciones primarias del hijo de Jacob Freud y Amalia Nathansohn, es significativo que, como anota Max Schur (1972, 1980, p. 415, n. 1), en yidis, Moira signifique temor, y no destino...

Freud parece verse permanentemente amenazado ante la "nobleza inalcanzable" de Nietzsche como ante su doble: esa presencia sacer (sagrada y prohibida) que se le adelanta en sus razonamientos, que se confunde consigo al punto de percibirse a sí mismo como encarnando una repetición no deliberada, que le presta palabras y define sus intereses y horizontes como si le leyera la mente, incluso como si, desde un más allá misterioso, la escribiera; como si adivinara sus pasos, convirtiéndolo en sombra. Presencia extraña que se vuelve familiar, y que vuelve a lo familiar, extraño. Freud teme perder su delicada imparcialidad y, por así decirlo, "quedar ciego" por efecto de la lectura de ese nada ficticio Hombre de Arena de quien espera la castración.

Freud, como un Edipo redivivo al que la verdad cegará y arrastrará a la desgracia, se reconoce prefigurado en esa letra: se aterra $\mathrm{y}$ se fascina al mismo tiempo ante ese "otro yo" admirado y aborrecido que pone en riesgo su preciada singularidad, y que actualizaresignifica al agresor (sádico pero poderoso) de su padre (víctima pero pusilánime); que hiere, que desprecia, que descubre, que crea y que ama, ique goza!, como y con lo que Freud sueña. Fantasma paterno ${ }^{21}$, hermano mayor en la línea schopenhaueriana, el doble pone en riesgo la identidad y sustrae el privilegio y la exclusividad del goce con lo prohibido. Lo admira por ser un descifrador de enigmas (sus enigmas, sus trabajosas soluciones), y por esa misma razón (entre otras) le teme y lo odia.

Se fascina ante el desprecio nietzscheano por lo bajo, lo mediocre, lo vulgar, y se irrita por la dificultad de disociar ese desdén-desdén por la "chusma" hipócrita que él mismo aborrecede sus connotaciones raciales-constitucionales: por la dificultad de disociarlo de sí mismo y del judaísmo. Freud lo incorpora y lo niega: quiere ser como Nietzsche sin saberlo, se sabe como él sin quererlo; lo devora pero lo mantiene a distancia: seducido y culpable, agradecido y receloso. Nietzsche es el recuerdo de lo impersonal latente en Freud, de lo propio-no propio que compulsivamente invoca y pretende conjurar, el nombre de lo íntimo-extraño que 
acoge y que lo habita, con toda la ambivalencia del padre, del hermano, del enemigo, del huésped, del destino (Moira), del deseo.

\section{Notas}

1 Como material complementario consúltese: Chapman y Chapman-Santana (2002), Gemes (2009), Latham (2011), Nössler (2006) y Straube (2010).

${ }^{2}$ Jones (1959, p. 367) indica sin titubeos que se trata de una "paráfrasis de Nietzsche".

${ }^{3}$ Otra explicación se hace más necesaria si se considera que ese mismo año Freud asistió a una lección sobre Nietzsche a cargo de Georges Brandes (Greer, 2002, p. 305).

4 Scavio, Cooper y Clift (1993) han visto este alejamiento que Freud establece con Nietzsche como una consecuencia de la disputa con Jung y Adler, dos de los lectores de Nietzsche en el movimiento psicoanalítico. Sin embargo, esto resulta improbable si se tiene en cuenta que precisamente a partir de 1914 (y hasta 1930) aparecería en La interpretación de los sueños un apéndice de autoría de Otto Rank en el que se valoraba a Nietzsche como un precursor del psicoanálisis.

${ }^{5}$ Sobre este tema véase Heller (en Golomb, 2001, pp. 201-205). Sobre las discusiones en la SPV y su importancia en la conformación del discurso psicoanalítico véase Vallejo (2008).

${ }^{6}$ Jones (1960, p. 362) refiere una síntesis interesante de las sesiones.

${ }^{7}$ Una reconstrucción similar en lengua inglesa la hace Roazen (2001).

${ }^{8} \mathrm{Al}$ respecto véase: Gasser (1997, pp. 7-29).

9 Heller (citado por Golomb, 2001, p. 212n) señala allí un error de traducción. Freud escribe: "Durante mi juventud, representaba para mí una nobleza fuera de mi alcance", "In meiner Jugend bedeutete er (Nietzsche) mir eine mir unzugängliche Vornehmheit" (Freud \& Zweig, 2000, p. 89), como figura en Assoun (1984, p. 40). Hecha la advertencia, transcribimos arriba la otra traducción, dado que, aunque incorrecta, nos ofrece la continuación de la carta, de gran relevancia aquí.

${ }^{10}$ Las mínimas diferencias con el lenguaje de Nietzsche que se producen en la traducción del texto psicoanalítico no deben hacernos cavilar sobre la inequívoca proveniencia nietzscheana del lenguaje freudiano: "Was ich Traum verschiebung genannt habe, könnte ich auch als Umwertung der psychischen Wertigkeiten bezeichnen". (Freud, 1901, p. 632). Atentos a la inspiración nietzscheana de Freud, en lengua inglesa umwertung se vierte por Transvaluation.

11 "Si bien es muy cierto que de las dos mitades de la vida, la mitad de la vigilia y la mitad del sueño, la primera nos parece mucho más privilegiada, importante, digna, merecedora de vivirse, más aún, la única vivida: yo afirmaría, sin embargo, aunque esto tenga toda la apariencia de una paradoja, que el sueño valora de manera cabalmente opuesta aquel fondo misterioso de nuestro ser del cual nosotros vivimos la apariencia" (Nietzsche, 1872, 1994, p. 56).

12 Jones (1960) narra muy brevemente la visita que él y Sachs hicieron durante el Congreso a la hermana de Nietzsche. La visita, sin mayores repercusiones, se planteó como una especie de reconocimiento del gran "escritor" como un precursor del psicoanálisis, único filósofo al que se le dio ese privilegio.

${ }^{13}$ Sánchez Pascual traduce "Del pálido delincuente" (Nietzsche, 1883, 1885, 2007b, pp. 66-68). Sobre el sentimiento inconsciente de culpa en Nietzsche y en Freud, compárese Bishop (1999).

${ }^{14}$ Allí Nietzsche (1883, 1885, 2007b, p. 142) no solo anuncia al superhombre; también 
declara que "Nunca ha habido todavía un superhombre". El padre de la horda no parece ser una ficción de un individuo preocupado por liberar al hombre del espíritu de la venganza...

${ }^{15}$ No menos sugerente es la reaparición del concepto precisamente en el texto antirreligioso por excelencia del corpus freudiano, El porvenir de una ilusión. En él, Freud (1927, 2004b, p. 17) se refiere a los "superhombres violentos", personificaciones del poder de la naturaleza y el destino contra los que el hombre (primitivo) indefenso quiere protegerse.

${ }^{16}$ Strachey escribe en nota al pie que en esa frase parecen resonar las palabras de Nietzsche. También se refiere Freud (1919, 1999, pp. 236, $238,246)$ a este fenómeno como la "repetición de lo igual", la "compulsión interior de repetición" y el "retorno no deliberado de lo igual".

${ }^{17}$ Sobre la filosofía política de Nietzsche es imprescindible la interpretación históricamente fundada de González-Varela (2010).

${ }^{18}$ Basta leer la "Dedicatoria a Voltaire" de Humano, demasiado humano, donde Nietzsche $(1878,2007 a$, p. 31) dice que este libro había nacido en Sorrento durante el invierno de 1876-1877.

${ }^{19}$ Acerca de la interpretación de Nietzsche como psicólogo se puede rastrear el artículo titulado "Nietzsche, ¿primer psicoanalista?" (Drivet, 2015).

${ }^{20}$ Roazen (2003) reconoce la identificación de Freud con Nietzsche (El anticristo) en la voluntad de transvalorar valores: "When Freud playfully identified himself, on a number of occasions, with the devil, he was doing so in the spirit of Nietzsche's kind of celebration of the virtues of transgression" (p. 203).

${ }^{21}$ Rudnytsky (1985) creyó ver en esta relación algo del orden de lo edípico.

\section{Referencias}

Andreas-Salomé, L. (2005). Friedrich Nietzsche en sus obras. Barcelona: Minúscula.

Assoun, P. L. (1984). Freud y Nietzsche. México: FCE.

Bishop, P. (1999). Estrangement from the Deed and the Memory thereof: Freud and Jung on the Pale Criminal in Nietzsche's Zarathustra. Orbis Litterarum 54(6), 424-438. doi: 10.1111/j.1600-0730.1999.tb00296.x

Chapman, A. H., \& Chapman-Santana, M. (2002). The impact of Nietzsche on Freud. Journal of Nervous and Mental Disease, 190(11), 783-785.

Derrida, J. (1986). La tarjeta postal. De Freud a Lacan y más allá. México: Siglo XXI.

Drivet, L. (2015). Nietzsche, ¿el primer psicoanalista?. (Tesis doctoral inédita). Universidad de Buenos Aires. Buenos Aires, Argentina.

Federn, E., \& Nunberg, H. (1975). Minutes of the Vienna Psychoanalytic Society (Tomos 1-4). Nueva York: Internacional University Press.

Freud, S. (1989). Epistolario (Tomo 3, Años 1910-1939). Buenos Aires: Hyspamérica.

Freud, S. (1991). La interpretación de los sueños. (Tomos 4-5). Buenos Aires: Amorrortu.

Freud, S. (1994). Cartas a Wilhelm Fliess (18871904). Buenos Aires: Amorrortu.

Freud, S. (1998). Presentación autobiográfica. (Tomo 20, pp. 1-70). Buenos Aires: Amorrortu.

Freud, S. (1999). Lo ominoso. (Tomo 17, pp. 215-252). Buenos Aires: Amorrortu. 
Freud, S. (2003a). Contribución a la historia del movimiento psicoanalítico. (Tomo 14, pp. 1-64). Buenos Aires: Amorrortu.

Freud, S. (2003b). Algunos tipos de carácter dilucidados por el trabajo psicoanalítico. (Tomo 14, pp. 313-340). Buenos Aires: Amorrortu.

Freud, S. (2004a). Psicología de las masas y análisis del yo. (Tomo 18, pp. 63-135). Buenos Aires: Amorrortu.

Freud, S. (2004b). El porvenir de una ilusión. (Tomo 21, pp. 1-55). Buenos Aires: Amorrortu.

Freud, S. (2004c). El malestar en la cultura. (Tomo 21, pp. 57-140). Buenos Aires: Amorrortu.

Freud, S. (2006a). Psicopatología de la vida cotidiana. (Tomo 6, pp. 1-270). Buenos Aires: Amorrortu.

Freud, S. (2006b). Puntualizaciones psicoanalíticas sobre un caso de paranoia. (Dementia paranoides) descrito autobiográficamente. (Tomo 12, pp. 1-76). Buenos Aires: Amorrortu.

Freud, S. (2006c). Más allá del principio del placer. (Tomo 18, pp. 1-62). Buenos Aires: Amorrortu.

Freud, S. (2006d). Nuevas conferencias de introducción al Psicoanálisis y otras obras. (Tomo 22, pp. 1-168). Buenos Aires: Amorrortu.

Freud, S. (2006e). El yo y el ello. (Tomo 19, pp. 1-65). Buenos Aires: Amorrortu.

Freud, S. (2006f). Moisés y la religión monoteista. (Tomo 23, pp. 1-208). Buenos Aires: Amorrortu.
Freud, S., \& Zweig,A. (2000). Correspondencia, 1927-1939. Barcelona: Gedisa.

Gasser, R. (1997). Nietzsche und Freud. Berlín: De Gruyter.

Gay, P. (2010). Freud: una vida de nuestro tiempo. Barcelona: Paidós.

Gemes, K. (2009). Freud and Nietzsche on Sublimation. Journal of Nietzsche Studies, $38,38-59$.

Golomb, J. (2001). Freud and Jewish Culture. Nueva York: Routledge.

Gómez, C. (1994). Alteridad y producción intelectual: Nietzsche, un ideal de Freud. Contextos, 12(23-24), 337-355.

González, N. (2010). Nietzsche Contra la democracia. El pensamiento político de Friedrich Nietzsche (1862-1872). España: Montesinos.

Greer, S. (2002). Freud's "bad conscience": The case of Nietzsche's Genealogy. Journal of the history of the behavioral sciences, 38(3), 303-15.

Groddeck, G. (1973). El libro del Ello. Cartas psicoanalíticas a una amiga. Madrid: Taurus.

Jones, E. (1959). Vida y obra de Sigmund Freud I. Infancia y juventud. El autoanálisis. La interpretación de los sueños. Buenos Aires: Nova.

Jones, E. (1960). Vida y obra de Sigmund Freud II. Los años de madurez, 1901-1919. Buenos Aires: Nova.

Latham, T. (2011). The Birth of Psychoanalysis: Nietzsche's Legacy and Influence on Freudian Thought. Recuperado de http:// www.duponttherapy.com/Dupont Therapy/Articles_files/The $\% 20 \mathrm{Birth} \% 20$ of $\% 20$ Psychoanalysis.pdf 
Lehrer, R. (1995). Nietzsche's presence in Freud's life and thought. On the origins of a psychology of dynamic inconscious mental funtioning. Nueva York: State University of New York Press.

Lukács, G. (1959). El asalto a la razón. La trayectoria del irracionalismo desde Schelling hasta Hitler (Trad. W. Roces). Buenos Aires: FCE.

Mann, T. (Ed.). (2000). La filosofía de Nietzsche a la luz de nuestra experiencia. En Schopenhauer, Nietzsche, Freud (Trad. A. Sánchez Pascual, pp. 89-135). Madrid: Alianza.

Miranda De Almeida, R. (1997). L'au-dela du plaisir. Une lecture de Nietzsche et Freud. (Tesis doctoral sin pubicar). Faculte des Lettres et Sciences Humaines, Universite de Metz.

Nietzsche, F. (1994). El nacimiento de la tragedia. Madrid: Alianza.

Nietzsche, F. (2007a). Humano, demasiado humano I. Un libro para espíritus libres. Madrid: Akal.

Nietzsche, F. (2007b). Asi habló Zaratustra. Madrid: Alianza.

Nietzsche, F. (2008). La genealogía de la moral. Buenos Aires: Alianza.

Nolte, E. (1990). Nietzschey el nietzscheanismo. Madrid: Alianza.

Nössler, E. (2006). Zur Aktualität der Moralkritik von Friedrich Nietzsche und Sigmund Freud. Múnich: GRIN Verlag.

Roazen, P. (1993). Meeting Freud's Family. Massachusetts: University of Massachusetts Press.
Roazen, P. (2001). Nietzsche and Freud. Two voices from the underground. En T. Yamamoto (Ed.), Philosophical Designs for a Socio-Cultural Transformation. Beyond Violence and the Modern Era (pp. 327-349). Japan: E.H.E.S.C.

Roazen, P. (2003). Cultural Foundation of Political Psychology. Nueva Jersey: Transaction Publishers, New Brunswick.

Rudnytsky, P. L. (1985). Nietzsche's oedipus. American Imago, 42, 413-439.

Scavio, M. J., Cooper, A., \& Clift, P. S. (1993). Freud's devaluation of Nietzsche. Psychohist Review, 21(3), 295-318.

Schur, M. (1980). Sigmund Freud. Enfermedad y muerte en su vida y en su obra (Trad. I. Menéndez, Vol. 2). Barcelona: Paidós.

Spielrein, S. (1995). Destruction as Cause of Becoming. Psychoanal. Contemp. Thought, 18, 85-118. Recuperado de http:/www.pep-web.org/

Straube, S. F. (2010). Nietzsche und S. Freud-ein Vergleich aus moralanthoropologischer Sicht. Múnich: GRIN Verlag.

Vallejo, M. (2008). Los miércoles por la noche, alrededor de Freud. La construcción del discurso psicoanalítico a la luz de las Actas de la Sociedad psicoanalítica de Viena. Buenos Aires: Letra Viva.

Vartzbed, E. (2003). La troisième oreille de Nietzsche. Essai sur un prècurseur de Freud. Paris: L'Harmattan.

Yerushalmi, Y. H. (1996). El Moisés de Freud. Judaismo terminable e interminable (Trad. H. Pons). Buenos Aires: Nueva Visión. 
